\title{
O projeto das ligas operárias do Rio Grande do Sul no início da República
}

Beatriz Ana Loner*

Resumo: Nos anos iniciais da República, o conjunto do bloco do trabalho, no estado gaúcho, tentou organizar-se para intervir politicamente, nacional e estadualmente, através das ligas operárias e da proposta de construção de um partido operário com expressão eleitoral. Esse projeto foi levado adiante principalmente pelas lideranças das três principais cidades gaúchas, Porto Alegre, Pelotas e Rio Grande. Entretanto, não conseguiram vencer os obstáculos que se antepuseram em seu caminho, em termos de organização, e também sofreram os efeitos da polarização partidária e, posteriormente, da guerra civil que devastou o estado, tendo o projeto fracassado, política e organizacionalmente, fechando-se também, após o período estudado, as possibilidades de uma participação independente dos trabalhadores na cena política gaúcha.

Palavras-chave: Operários republicanos. Ligas operárias. Partido operário. Primeira República. Mundos do trabalho.

\section{Introdução}

A proposta deste artigo é revisitar a conjuntura da proclamação da República e dos anos da guerra civil no estado do Rio Grande

\footnotetext{
* Professora-Associada da Universidade Federal de Pelotas (UFPel), docente dos programas de Mestrado em Ciências Sociais e em História dessa instituição. E-mail: bialoner@yahoo.com.br.
}

Anos 90, Porto Alegre, v. 17, n. 31, p. 111-143, jul. 2010 
do Sul descrevendo a nascente organização dos setores vinculados ao trabalho e analisando a forma pela qual pretendiam inserir-se nas instâncias políticas do país. Minha análise, portanto, estará focada apenas dentro do bloco do trabalho, utilizando-se de outros autores (BAK, 2000; PACHECO, 2001) no que tange às suas relações com o estado. As fontes de consulta foram jornais e estatutos das associações que, embora suficientes para denotar as articulações entre as organizações, não permitiram aprofundar o nível dessas relações, devido à falta de ofícios, atas e outros documentos próprios de cada associação. O objetivo que motivou este estudo foi desvendar o móvel das ações daquelas primeiras lideranças e observar as possibilidades e limites de um trabalho em comum entre elas.

As primeiras tentativas de organização política dos trabalhadores foram feitas dentro do bloco dos interesses do trabalho, acompanhando a situação da sociedade brasileira, que apenas iniciara seu processo de diferenciação urbana. Tendo que dar seus primeiros passos numa sociedade ainda voltada prioritariamente aos interesses rurais e que atendia suas necessidades de produtos manufaturados ou industrializados via importação europeia, é quase natural que o setor do trabalho pensasse em lutar unido para o reconhecimento da importância da indústria nacional. Sucederam-se várias tentativas naqueles primeiros anos, algumas regionais, outras nacionais, mais ou menos articuladas entre si, tentando encontrar formas de participação política e expressão de seus interesses, com variados graus de definição ideológica e articulação interna.

Àquela altura, dava-se destaque, através dos jornais, a quaisquer propostas de organização, refletindo um momento de indefinição e perda de referenciais tradicionais, por parte de vários setores, que não se haviam preparado para as fortes transformações pelas quais passava a sociedade brasileira desde meados da década de 1880, com o fim da escravidão, a chegada dos imigrantes e a proclamação da República. Segundo Pansardi (1998), essas transformações assinalavam, para os trabalhadores, ao lado de sua constituição formal como sujeito de direito, pela implantação do direito burguês no Brasil, as estruturas burocratizadas de acesso e, se possível, interferência junto ao Estado. Entre 1888 e 1891 "criou-se as condições para que o operariado e a burguesia se firmassem como classes participantes do 
jogo político e adquirissem consciência de si e ao mesmo tempo do outro" (PANSARDI, 1998, p. 87).

$O$ fato do setor do trabalho ainda apresentar-se indistinto em seus componentes internos nos primeiros anos da República permitia que se vislumbrasse a possibilidade de constituição de um bloco, forte pelo seu número e por sua abrangência, que estivesse em posição favorável para lutar pelos interesses da nascente indústria e do trabalho. Um estudo mais cuidadoso dos vários manifestos e discursos feitos ou dirigidos a esse setor evidenciam que esse era o caminho pensado para seu crescimento e fortalecimento.

Nessas condições, as reivindicações propriamente operárias, como delimitação da jornada de trabalho, melhor remuneração, proteção aos trabalhadores menores de idade ou as mulheres, tinham que disputar espaço, mesmo em programas de partidos ditos operários, com outras que incluíam proteção às indústrias e ao comércio, menor regulamentação fiscal e várias medidas que incluíam pensar na população como um todo, e não especificamente em interesses operários. A reorientação política necessária para a disputa na arena republicana ainda não estava feita, por parte de muitos, e desse modo as propostas de vários setores ainda apresentavam possibilidades de discussão e flexibilidade.

Foi possível assistir, naquele momento, empresários com muitos capitais participando, como delegados, de encontros operários nacionais ou sendo escolhidos como candidatos de partidos operários. Em troca, o rígido Partido Republicano Rio-Grandense (PRR) seria acusado de estar dando espaço a ideias socialistas, por ter publicado manifesto de um pretenso partido operário em seu jornal, e a oposição não tardará a falar em vendaval socialista e anarquia, ao referir-se aos castilhistas, na tentativa de ligá-los a essas propostas. Lançado, talvez, como balão de ensaio para ver a penetração de propostas mais radicais na sociedade gaúcha, o manifesto tentava harmonizar propostas como a proteção à produção nacional, presente em vários artigos - inclusive na proposta de julgamento e execução em 48 horas de contrabandistas (art. 20\%) -, e o fim de vários impostos internos, com a fiscalização da situação do proletário, ensino público, nivelação gradativa de fortunas e restrições ao direito de herança. 
O resultado foi uma proposta extremamente autoritária e voltada ao Estado, ao qual era atribuído grande poder de intervenção, reorganização administrativa e militar, possuindo veleidades imperialistas (anexação ao Brasil de pequenos Estados limítrofes). Exaltava a liberdade de imprensa, de expressão e pensamento e falava em sufrágio universal, também prevendo direitos iguais às mulheres, o que eram propostas avançadas para a época, mas instituía o casamento obrigatório para ambos os sexos e o recrutamento compulsório para o exército. ${ }^{1}$ Seu próprio conteúdo radical, mesclado de propostas contraditórias, algumas em desconformidade com o socialismo europeu, estabelece a dúvida sobre quem teriam sido seus autores.

Ao publicá-lo, o jornal $A$ Federação afirmou que "encontrou na rua","um avulso" de obra de anônimo "Partido Operário". Os jornais oposicionistas sobressaltaram-se com sua publicação e o criticaram de forma contundente, como "programa da anarquia", proveniente de planta exótica", que não vingaria na sociedade brasileira. Entretanto, seu espanto levanta a dúvida que estava por trás de suas críticas: poderiam os positivistas do PRR terem simpatias por tais ideias? ${ }^{2} A$ Reforma discutiu a contradição entre a Federação não reconhecer os liberais como um partido e "saúda[r] o aparecimento do Partido Socialista, que por enquanto se compõe apenas de dezenas de indivíduos e clandestinamente espalha seu programa, ao qual deu circulação a própria folha oficial do governo!"’3 Com fria lógica, concluía afirmando que se o socialismo se alicerçar no Brasil, a Federação viria buscar o apoio deles, pois teriam que unir-se contra essa doutrina.

Enquanto as oligarquias se alvoroçavam com o programa, dentro do bloco do trabalho a situação era diferente. O jornal O Trabalho Nacional irá dizer que nada viu de errado na publicação do manifesto pela Federação, pois o entendeu como uma peça de propaganda, que deveria ser respeitada como tal, mesmo considerando que no Brasil não havia questão social, pois existia trabalho para todos. Como contribuição ao debate, estampava carta do imperador alemão sobre necessárias melhorias no tratamento aos trabalhadores na sociedade capitalista. ${ }^{4}$ Por último, e sem fazer menção às suas contradições internas, esse mesmo manifesto foi saudado entusias- 
ticamente pelos representantes constituídos do operariado nacional no Rio de Janeiro, sendo utilizado como propaganda contra outra liderança carioca, a de Cruz e Silva. ${ }^{5}$ (CARONE, 1984, p. 297).

As repercussões que esse manifesto despertou podem ser mais bem explicadas dentro da conjuntura da proclamação da República. Em parte porque ela sinalizou a abertura de novas chances de participação, incentivando todos os setores a buscar por formas efetivas de inclusão no novo sistema político que se inaugurava no país. Segundo Pádua (1985), as classes médias urbanas, nas quais se situavam alguns desses "representantes operários", poderiam ser vistas como uma fonte de legitimidade para os militares e o grupo que havia tomado o poder, naquele momento, o que tornava os governos mais sensíveis a suas reivindicações.

Naquela conjuntura, aos trabalhadores (os que vivem do próprio trabalho manual, numa aproximação possível para aqueles anos) eram dirigidas várias interpelações políticas, algumas os entendendo como agentes próprios (caso do socialismo e/ou anarquismo) e outras os tratando como coadjuvantes (caso das propostas das ligas e dos empresários). Contudo, havia uma primeira interpelação, que vinha através da sua colocação como cidadãos, como parte da nova sociedade, criada com o fim do trabalho escravo e a proclamação da República. Essa última interpelação foi muito forte num primeiro momento, ocupando espaços mesmo entre as lideranças, porque a proposta de república conseguiu ser vista como a solução para acabar com os antigos males, saneando a vida política da nação. Na trajetória das primeiras lideranças do movimento organizado dos trabalhadores, houve uma espécie de "estágio republicano", no desenvolvimento de sua consciência de classe, exceto para aquelas que, por não serem nacionais ou por estarem estabelecidas em comunidades de imigrantes, tinham já outra experiência associativa ou uma definição ideológica mais aprofundada.

\section{Aorganização classista nos primeiros anos no interior do estado}

Houve esforços organizativos e inclusive mobilizações de categorias antes do período republicano, particularmente na última década 
do Império. De fato, foi a partir de 1880 que várias categorias iniciaram sua organização em entidades mutualistas, entre as quais a questão da representação de interesses já disputava espaço com a questão previdenciária. Naqueles anos, a organização de interesses corporativos, econômicos ou políticos era vista como o caminho para o progresso e a modernização, devido ao exemplo vindo da Europa.

Com a proclamação, houve um grande crescimento da organização gremial, com a república sendo entendida como ruptura com características negativas para a participação política e o desenvolvimento econômico, como: burocracia, apadrinhamento, apropriação do Estado por interesses particulares, corrupção e ineficiência administrativa. Eram os setores artesanais e/ou empresariais, estabelecidos nas cidades, os que mais acompanhavam o debate sobre a forma de governo e também os que possuíam condições de interpretar e buscar se beneficiar da mudança política ocorrida.

Analisando as primeiras propostas no setor, vê-se o desenvolvimento de uma ideia comum, a formação de ligas ou partidos, chamados de operários, mas que compreendiam os interesses conjugados de empregados, patrões, artistas e outros tipos de assalariados. Uma associação política de amplo espectro, em resumo, ideal para formar uma grande frente do setor do trabalho no Brasil. A sua base era municipal ou, no máximo, estadual, estando presente a ideia de formar federações nacionais, mais evidentes no caso de ligas ou centros operários, que, por terem uma proposta de maior diversidade de objetivos (econômicos e políticos, ao mesmo tempo), aspiravam a uma expressão nacional para serem representados junto ao governo federal. A seguir, será vista a evolução da organização nas três principais cidades gaúchas.

A organização industrial no estado foi iniciada em Pelotas com a fundação do Centro Agrícolo-Industrial em 1887, entidade de charqueadores, fazendeiros e industriais que fundou e manteve uma revista, O Sul do Brasil, na qual se defendiam interesses dos escravocratas sobre o fim da escravidão, mas, subsidiariamente, se tratava de assuntos da indústria e dos produtores em geral, buscando promover o desenvolvimento econômico da região. Devido a essa mescla de interesses diversos e ao desapontamento do setor charqueador 
com a maneira como foi feita a abolição, essa associação não conseguiu manter-se, desaparecendo em meados de 1888, inclusive porque abrigava interesses divergentes em torno da tarifa especial, a próxima grande luta do setor do trabalho.

Essa tarifa, proposta pelo gabinete liberal e solicitada pelas grandes praças importadoras, pretendia combater o contrabando permitindo a mercadoria estrangeira importada legalmente beneficiarse de uma tarifa de importação menor, com o que chegaria mais barato ao mercado. Com isso, terminava-se reduzindo o mercado para os produtos similares aos importados, produzidos pelas fábricas e manufaturas nacionais, levantando a oposição de todo o setor industrial, especialmente dos ramos de chapéus e calçados. Na luta contra essa tarifa, os industriais desses ramos estiveram sozinhos, pois os estancieiros e charqueadores não se viam motivados a auxiliá-los.

Dessa forma, os industriais e artesãos se viram obrigados a formar associações de defesa próprias do setor, base da criação das ligas ou centros operários, que proliferaram em várias cidades. Em Pelotas, formou-se, ainda em setembro de 1888, o Centro Cooperador dos Fabricantes de Calçados, que, em março de 1889 ampliou-se no Congresso Operário, reunindo toda a sorte de fabricantes e donos de oficinas da cidade, bem como seus empregados. Essa era uma entidade de setores federados, cuja incompatibilidade com a necessidade de uma direção centralizada os fez transformá-la na Liga Operária em 21 de julho de 1890.

Por alguns anos, a liga pelotense abrigará a pretensão de ser a porta-voz dos anseios e interesses dos industriais e dos operários da cidade. Essa associação rapidamente desenvolveu a busca de representação e participação política regional, discutindo e apoiando candidatos para eleições e até apresentando candidatos próprios. Em outra linha de intervenção, fazia-se presente em todos os encontros nacionais de trabalhadores, gestionando pela organização nacional. Deve-se ressaltar que o escopo de articulação das ligas, regional e nacionalmente, era um objetivo mais presente na atuação da liga pelotense e sua congênere rio-grandense, nascida a partir da atuação de um mesmo mentor, o jornalista português João da Costa Fortinho. 
Ele esteve presente desde 1887 em Pelotas no Centro Agrícolo-Industrial (como seu secretário e diretor da revista O Sul do Brasil), teve íntima ligação com governos da região do Prata e tentava passar uma proposta de desenvolvimento da indústria nacional, alicerçada no associativismo e na representação de interesses. Muito articulado e com boas relações no Rio de Janeiro, lutava pela criação de uma associação nacional da indústria e agricultura no país, correspondendo-se com a Sociedade Protetora da Indústria Nacional, com sede na capital. Maçom, Fortinho era uma pessoa excepcional em termos de capacidade organizativa, e foi também o idealizador das tentativas de articulação entre essas associações do interior e aquela de Porto Alegre, e da proposta de uma confederação nacional das ligas que trabalhasse em prol do desenvolvimento das indústrias brasileiras, desenvolvendo ativa correspondência com sociedades do centro do país.

A fundação do Centro Industrial Agrícola de Rio Grande, em 17 de outubro de 1888, ocorreu por inspiração sua, que esteve presente na reunião, que já vinha se reunindo com Rheingantz e outros industriais da cidade. ${ }^{6}$ Embora comprometido com essa proposta e tendo seu nome sondado para secretário e editor de $O$ Trabalho Nacional, Fortinho mudou-se para o Rio de Janeiro por motivos pessoais, o que representou um revés na organização do movimento no estado. Lá, ele se dedicou aos negócios e continuou com tentativas de organização dos interesses da indústria. ${ }^{7}$

Mesmo assim, a proposta continuou de pé e pretendia englobar o setor agrícola, pecuário, manufatureiro e fabril. ${ }^{8}$ Os fins da associação passavam pela luta em prol da industrialização e organização do setor, buscando a articulação nacional:

Consta que há ideia de fundar nesta cidade uma associação industrial que, com a que já existe em Pelotas e a que se pretende fundar em Porto Alegre, constituirão um elemento poderoso em favor da indústria da província. A sociedade que conjuntamente com suas congêneres das outras cidades se corresponderá com a Sociedade Protetora da Indústria Nacional, do Rio de Janeiro, terá mais ou menos os mesmos 
fins da que já existe em Pelotas [segue-se cópia dos objetivos do Centro Agrícolo-Industrial de Pelotas]. (Diário de Pelotas, 14 out. 1888).

A associação editou o jornal O Trabalho Nacional, criado a 9 de setembro de 1889, por dispositivo estatutário da sociedade, tendo existido até outubro de 1890 de modo regular e apresentando folhas esparsas até abril de 1891, editado por João de Saldanha, jornalista português e partidário da restauração monárquica.

Embora tivesse pessoas de peso, como o industrial Rheingantz, ${ }^{9}$ seu presidente de honra e sócios da futura indústria Leal Santos entre seus diretores, essa associação debateu-se, até seu desaparecimento, contra o que chamava de "apatia do seu meio". Em relatório da diretoria do ano de 1889, é registrado que, fundada com 31 associados, tinha apenas pouco mais que o dobro disso ao início do ano seguinte. ${ }^{10}$

Numa tentativa de incrementar sua atuação e ampliar seus quadros, realizou-se sua fusão com o Grêmio Artístico e Industrial, que estava em processo de organização ${ }^{11}$ e potencialmente possuía uma base social mais ampla, incluindo artesãos e operários especializados. Realizando a fusão depois de uma sequência de assembleias em que não se conseguiu reunir sequer a própria diretoria de ambas, a fragilidade da proposta tornou-se cada vez mais evidente, levando à extinção da sociedade.

Desde fins de 1890 existia outra sociedade composta apenas de trabalhadores pardos ou negros, a Sociedade Cooperativa Filhos do Trabalho, que em 1892, provavelmente formará a base para a criação da Liga Operária de Rio Grande. ${ }^{12}$ Marçal (1985, p. 62) indica que também houve uma "União do Trabalho", formada apenas por imigrantes socialistas alemães em Rio Grande naquele mesmo ano. Entretanto, para Koval (1982, p. 87) essa entidade localizava-se em Porto Alegre: "Em 1892 os trabalhadores de Porto Alegre organizaram por iniciativa de imigrantes alemães a União do Trabalho". A única referência a essa associação é o artigo de José Linhares (1963, p. 28), que diz textualmente: "Assim, em 1892, os trabalhadores gaúchos da cidade de Rio Grande, sob a influência 
de alemães ali radicados, fundaram a União do Trabalho”, sem citar nenhuma fonte comprobatória. Por outro lado, essa associação não foi encontrada em nenhum outro documento ou notícia, nos jornais em Rio Grande ou sobre a cidade. Consultando a integra do relatório da Comissão Executiva do Partido Operário do Brasil ao Congresso da Internacional em Zurique, citado por Marçal (1985), não aparece nenhuma referência a essa União do Trabalho. ${ }^{13}$ Mesmo Koval (1982), que só cita o texto de Linhares, coloca Porto Alegre em lugar da cidade de Rio Grande. Como era frequente a confusão, na documentação de militantes, entre o estado do Rio Grande do Sul (às vezes nominado apenas como 'Rio Grande') e a cidade de Rio Grande, pode ter acontecido que sua sede tenha sido mesmo em Porto Alegre. Nesse caso, ela poderia ser simplesmente a própria Allgemeiner Arbeiter Verein, que foi fundada nesse mesmo ano na capital por imigrantes alemães e socialistas, a qual, numa tradução livre para o português, pode ser entendida como "União Geral do Trabalho", o que confirmaria a versão de Koval (1982).

\section{A organização na capital}

Em 25 de setembro de 1887, organizou-se O Clube Artístico Porto-Alegrense, ${ }^{14}$ do qual só foram encontradas notícias até outubro do ano seguinte. Reunia artesãos nacionais e estrangeiros, a julgar pelas nominatas recuperadas de sua direção. Esse clube teve como diretores lideranças depois encontradas na União Operária, criada em julho de 1888 e esse, ao lado de não restringir seus sócios de forma étnica, é o motivo de ser colocado aqui, pois ao romper os laços de nacionalidade ou etnia, parece indicar um modo mais amplo de organização classista, que estará presente nas sociedades em estudo. Ampliando ainda mais esse viés, a Sociedade de Beneficência União Operária articulava operários, artesãos e empresários, com caráter mutualista, e teve rápido crescimento, pois "conta já mais de duzentos sócios, não tendo ainda um mês de existência, o que registramos com prazer". ${ }^{15}$ Com eleições semestrais e implantação em várias oficinas e fábricas, nas quais possuía diretores e fazia 
reuniões, ela criou aulas públicas e biblioteca para seus sócios, organizando bazar de prendas para obter recursos, além de lançar um jornal, O Operário, em 20 de janeiro de 1889. Em seu primeiro número, ela se congratulava por ter apoiado um candidato operário nas eleições de dezembro, que terminou sendo eleito, mas através de uma negociação com o Partido Liberal (MORITZ, 1939, p. 10). Ora, sua eleição dessa forma foi contrária ao que desejava a associação, que dava a essa candidatura um componente de protesto:

Em nosso manifesto, antes da eleição, fizemos patente aos nossos concidadãos que o candidato das artes, José Manuel da Silva Só, não tendo ligação com nenhum dos partidos militantes, nem esperança de ser eleito, qualquer votação que obtivesse, serviria de reforço ao nosso protesto, dirigido ao governo imperial contra a decretação e execução da tarifa especial integral e nesse terreno pleiteamos a eleição. $(O$ Operário, 20 jan. 1889).

Sintomaticamente, não é dito que esse candidato foi eleito, muito menos do apoio partidário que recebeu. Brevemente, ele será considerado "traidor dos interesses da classe", por seguir a orientação do Partido Liberal, que defendia a "tarifa especial", contra a qual se lutava. O que interessa registrar é que desde seu nascimento, a organização do trabalho em Porto Alegre estava voltada para as questões políticas.

Tendo também o objetivo de posicionar-se contra a tarifa especial foi feita uma reunião de operários de Porto Alegre com uma delegação vinda de São Leopoldo, em 13 de janeiro de 1889, a qual culminou com a criação da Liga Agrícola e Industrial (LAI), chamada também de Liga Operária Industrial pelos jornais. ${ }^{16}$ Aparentemente, a discussão para a formação da nova entidade já vinha acontecendo há algum tempo, pois nessa mesma reunião é assinado seu programa e se elege sua diretoria definitiva, que contempla alguns militantes da União Operária da capital, provavelmente com lideranças de São Leopoldo, alguns dos quais ficarão conhecidos naqueles breves e intensos anos de disputas políticas. 
Pelo Sr. Cunha e Silva foi discutido o projeto do programa do novo partido - Liga Agrícola e Industrial. A síntese desse programa, que dentro em poucos dias publicaremos integralmente, é esta: protecionismo, vias de comunicação, extensão do direito do voto, imposto equitativo, policiamento. Falaram ainda outros oradores e por último o Sr. Francisco José de Mesquita, que lembrou a necessidade de cogitar-se da forma de governo, sendo aplaudido. Em seguida foi assinado o programa e procedeu-se à eleição da diretoria definitiva, que ficou assim organizada: presidente Francisco Herzog, vice-presidente João José de Brito, $1^{\circ}$ secretário Nicolau T. de Soledade, $2^{\circ}$ secretário Guilherme Roth, $3^{\circ}$ secretário José Scotto, tesoureiro Manoel Ignácio Rodrigues. Comissão executiva João Steenhagem, Joaquim Alves dos Santos Cunha e Silva e Fernando Berts Chinger [Bertschinger]. (Onze de Junho, 17 jan. 1889).

Obviamente, essa comunhão de interesses não foi obra de um dia para o outro, representando o resultado de várias reuniões e contatos trocados entre eles. O programa não é aventado ou sugerido, mas sim assinado, a diretoria é eleita e considerada definitiva, ou seja, são muitos os pontos que deixam claro tratar-se da execução de um projeto já longamente preparado. A falta de estudos com relação à organização do trabalho na região de colonização alemã impede um aprofundamento da questão. Quanto a Porto Alegre, há evidências da proximidade entre a LAI e a União Operária, como o fato de que muitas lideranças importantes desta estarão na diretoria daquela, ao mesmo tempo. As duas sociedades também são encontradas participando (e até chamando conjuntamente) de mobilizações do setor, contra o Banco Emissor, em abril de 1890 ou em manifestações de cunho acentuadamente político, como a recepção ao ministro demissionário da Agricultura, Demétrio Ribeiro, ou ainda nos acontecimentos do mês de maio de $1890 .{ }^{17}$ Talvez a questão resida no fato de que a LAI tinha uma abrangência maior, pois fora fundada em foro comum de operários de Porto Alegre e São Leopoldo. ${ }^{18}$ Contudo, também deve considerar-se a função política a ser desempenhada por ela. 
A liga surge como uma organização política e queria funcionar como um novo partido, do setor do trabalho. $\mathrm{Na}$ verdade, a Liga Agrícola e Industrial é reconhecida, inclusive por suas congêneres do interior, como a presumível liderança estadual do projeto das ligas no estado. Entretanto, ela praticamente submerge na disputa política entre os grupos republicanos de Porto Alegre, e vai ter pouca expressão no projeto comum de aliança ou Federação das Ligas, exceto ao solicitar apoio para as ações políticas às sociedades do interior, no que será auxiliada pela de Pelotas.

A LAI vai ter muita atuação, seja específica, na luta contra a tarifa especial e o Banco Emissor, seja política, com suas lideranças estando próximas do Partido Republicano Rio-Grandense. Essa mesma proximidade marcará seu destino final, pois a partir de agosto de 1891, seguindo a divisão das lideranças republicanas, serão formadas duas novas entidades, a Liga Operária, que seguirá a orientação dos castilhistas, e o Centro Operário, que será simpática aos dissidentes republicanos, Barros Cassal e Demétrio Ribeiro. Nesse momento, a associação que continuará apostando - e inclusive se dedicando mais ao projeto de formação de um partido operário - será o Centro Operário. Seu programa, depois de fazer várias ponderações sobre o regime republicano, com o qual se identifica, e seu governo frente ao qual apresenta uma posição crítica -, termina propondo novamente a criação de um partido autônomo dos trabalhadores:

Bem se vê, pelo exposto, que se devemos confessar-nos gratos ao governo pelas suas intenções para com o proletariado, não podemos deixar de reprovar outros atos prejudiciais à classe que representamos. Resulta daí a nossa atitude excepcional: devemos formar um partido político que, não hostilizando o governo atual, também não o deve apoiar incondicionalmente; que colocando-se no terreno legal, intervenha na gestão dos negócios públicos de nossa pátria, para que sejam guardados os interesses tanto das classes produtoras como das demais camadas sociais. 
Mas, para que o partido seja grande e forte, para que para o futuro do operário rio-grandense seja na comunhão brasileira, considerado um cidadão útil à sociedade, torna-se mister que o Centro Operário seja o verdadeiro núcleo desse movimento, para que o proletariado do estado do RS, se comunique com ele. Só assim, será possível levantar a indústria nacional ao posto que ela tem jus. (Jornal do Commercio, 2 out. 1890, grifo no original).

O Centro Operário pede o concurso dos companheiros de Rio Grande, Pelotas, Uruguaiana e outras comunidades organizadas na empreitada e conclama à união e também ao apoio de todos os operários gaúchos. Já a Liga Operária tem objetivos bem mais modestos.

Bak, em obra ainda inédita, vê essa cisão como consequência do apoio dispensado pela LAI aos candidatos oficiais do PRR nas eleições de setembro de 1890 em detrimento dos candidatos dissidentes, e interpreta a atuação do Centro Operário como vinculada estreitamente à polarização republicana, naquele ano e pelo menos até o golpe que destitui Castilhos do governo em novembro de 1891. Mesmo assim, assinala que eles procuraram manter uma política de não alinhamento automático em relação aos dissidentes republicanos. Segundo sua análise em trabalho anterior (BAK, 2000), o Centro Operário vai procurar diferenciar os trabalhadores manuais dos empresários, inclusive lançando panfletos em alemão. Ele tem influência visível no meio dessa colônia, pois na cidade de Montenegro se funda uma agremiação denominada Congresso dos Proletários, afiliada ao Centro Operário porto-alegrense. ${ }^{19}$

Enquanto isso, aqueles "homens do trabalho" que se mantiveram fiéis a Castilhos criaram nova entidade, a Liga Operária, em reuniões iniciadas ainda em dezembro de $1890 .^{20}$ Ela tem Francisco José de Mesquita, do Arsenal da Guerra, como presidente e se alinha ao PRR e a Castilhos, assumindo muito de seu discurso e tendo um programa bem mais moderado em relação à outra associação, constando de propostas passíveis de serem apoiadas pelo PRR, como a criação de um montepio e liceu de artes e ofícios, educação leiga e livre, impostos equitativos e criação de um tribunal para resolver disputas entre patrões e operários. Bak (2000) e Pacheco 
(2001) indicam uma situação econômica mais alta (ou estável) de sua direção, em termos do grupo rival, com a presença de empresários e funcionários públicos na liga.

Novamente, tanto Bak quanto Pacheco chamam a atenção para uma sutil, mas significativa diferença entre os dois centros: enquanto a Liga Operária reivindica-se representante das classes produtoras, o Centro Operário prefere dirigir-se ao operariado. Pacheco (2001) analisa os anos de 1889 a 1891 a partir do conceito de cidadania e do modo como os cidadãos de menores recursos "tomaram as ruas" e apoiaram os republicanos na capital. Bak (2000) procura analisar as posições dos trabalhadores e suas relações com o governo nas várias conjunturas. Recentemente, aprofundando sua análise sobre a forma como era praticada pelos republicanos a divisa comteana de incorporação do proletariado, chegará à conclusão de que coube aos dissidentes republicanos formular propostas que mais visavam essa incorporação, constatando que, nos grupos de lideranças operárias que divergiram de Castilhos, não havia um alinhamento automático com o partido dissidente, tal como este impôs aos trabalhadores que seguiram as suas determinações. ${ }^{21}$

Contudo, algumas lideranças serão marcadas irremediavelmente por suas posições políticas: o alfaiate italiano Guelfo Zaniratti, de liderança da LAI e do Centro Operário ocupará o cargo de subdelegado de polícia na capital durante o governo dos dissidentes, e acompanhará Barros Cassal em seu exílio no Uruguai, logo a seguir. Já Francisco Mesquita, líder do Arsenal da Guerra em Porto Alegre e responsável por boa parte da capacidade intimidatória apresentada por grupos de trabalhadores a serviço dos castilhistas, vinculado à LAI e à Liga Operária, será tenente na guerra civil.

Assim, em Porto Alegre, os anos de 1890 e 1891 estarão marcados pela instrumentalização das reivindicações dos setores do trabalho, por parte de grupos rivais, oriundos do republicanismo. Enquanto isso, o interior conserva-se mais preservado dessa influência política explícita (embora também lá existam vários operários republicanos) e, portanto, terá maiores condições de levar avante a proposta de Federação das Ligas. 
Um exemplo da expressão desse projeto foi dado quando da formação de uma chapa operária para a eleição da Constituinte Estadual. O Centro Operário apostou alto naquele momento, indicando três de seus diretores para o pleito (Guelfo Zaniratti, Bartolomeu Chana e João Von Held) e aceitando dois outros nomeados por seus associados do interior: Demétrio Seixas, pelo Congresso dos Proletários de Montenegro, e Ismael Simões Lopes, pela Liga de Pelotas. Além deles, também foram indicados, em assembleia dita "das classes produtoras" em Porto Alegre, dia 29 de março, os nomes de: Francisco Augusto Guimarães, Guilherme Hoffmann e José Pedro Alves. As escolhas da assembleia porto-alegrense foram aceitas pela União Republicana, que reunia os dissidentes, embora posteriormente, devido ao pouco espaço, apenas os dois últimos nomes constassem da chapa conjunta com a União Nacional. ${ }^{22}$

Quanto à sua proveniência de classe, as lideranças do Centro Operário eram artesãos ou pequenos empresários. José Pedro Alves era dono de uma fábrica e depois será presidente da Associação Comercial de Porto Alegre. Ele e Bartolomeu Chana (dono de tinturaria e com outras atividades empresariais) assinarão a Ata de Proclamação da Junta Governativa do estado do Rio Grande do Sul em 12 de novembro de 1891 (MORITZ, 1939, p. 262-264), que legaliza a derrubada de Castilhos. Outro participante dessa lista estará presente nesse episódio, mas acompanhando Castilhos, Ismael Simões Lopes. A inclusão do seu nome como candidato pelo Partido Operário representava, até certo ponto, a medida do compromisso do Centro Operário com o projeto comum das ligas, pois já então ele era castilhista, constando também da nominata do PRR, pelo qual será eleito. Sua eleição, entretanto, nunca será considerada pelo conjunto do operariado como representativa, pela sua posição política e de classe.

O único candidato eleito que os representará na Constituinte é um industrial, João Steenhagen, que sairá pela lista dos candidatos castilhistas, aclamada em reunião convocada pelo PRR, a qual a Liga Operária de Porto Alegre conclamou seus filiados a participar. Nessa espécie de pré-eleição à Constituinte (apenas o PRR elegeu candidatos, pela forma de contagem dos resultados) foi apresentado um abaixo assinado com 62 assinaturas, mais de 10\% do total dos 
presentes, propondo o nome de Cunha e Silva, liderança da classe como candidato, mas que não foi aceito, tendo os trabalhadores que se contentarem com quem o PRR havia escolhido para representá-los (PACHECO, 2001, p. 118).

Antes de encerrar este ponto é necessário discutir até que ponto estava realmente em jogo a proposta de organização de um partido operário e o quanto estavam comprometidos com ela os operários porto-alegrenses. Aqui, inclino-me a pensar que a proposta realmente existia, embora em alguns momentos ficasse submersa sob o peso de seu apoio aos grupos republicanos. No caso da eleição à Constituinte, ela torna-se mais evidente, como se pode ver na notícia do Correio Mercantil (17 abr. 1891) intitulada "Partido Operário", na qual se diz que este, "em combinação com as associações operárias do estado, apresentou, por seu diretório na capital, a seguinte chapa de candidatos a membros do Congresso Constituinte", seguindo-se a nominata dos candidatos do Centro Operário.

Assim, o centro é tratado como diretório de um partido, e suas próprias atitudes, aceitando nomes propostos por outros fóruns, sem questioná-los, além de vir a público pedir votos para todos os oito candidatos de sua nominata e não apenas para aqueles com os quais mais simpatizavam, ${ }^{23}$ autorizam essa interpretação. Também se pode utilizar o insuspeito depoimento de Simões Lopes, que, ao ser confirmado candidato pela Liga de Pelotas, declarou que "marcharia com as Ligas Operárias, aceitando as deliberações destas de acordo com os princípios democráticos conservadores e reservando para si o direito de operar em todos os atos alheios às determinações destas"(A Pátria, 9 abr. 1891). Havia a consciência de uma proposta em andamento, pela qual ele aceitava participar, embora no restante continuasse atuando de acordo com o PRR, partido do qual era liderança na cidade.

Do mesmo modo, é significativo ver que, anos depois, as críticas sobre a atuação nessa conjuntura, do próprio movimento, afirmavam a existência real do partido operário, embora o apresentando de modo fluido e amplo. Entre as publicadas, há uma carta aberta, sem assinatura, em que seu autor acusa Francisco Herzog, João Steenhagem, Felippe Seibert, Kappel, João Von Held, Bartholomeu Chana e Nicolau Tolentino da Soledade, todos 
participantes das associações citadas, de terem destruído o partido, atrelando-o aos interesses dos partidos tradicionais: "os senhores quiseram, mistificados pelos vultos dos partidos republicano, dissidente e federal, arrastar o partido operário por caminhos intransitáveis para ele [...] o resultado foi o esfacelamento total do mesmo partido". Anteriormente à sua atuação, não só o partido existiria, mas era forte:

A agremiação proletária, quando entregou-se direta ou indiretamente em vossas mãos, foi crente de que o entusiasmo que os senhores mostravam pelo seu porvir não arrefecesse; ela era forte, unida, embora não fosse bastante habilmente dirigida. (A Gazetinha, 15 jan. 1893).

Pode-se questionar essa afirmação como muito otimista, mas se ela for relativizada para o que era possível, em termos de organização, naqueles anos, guarda muito de seu sentido. Deve-se pensar que o autor quer o renascimento dessa associação, portanto, é importante indicar que havia uma consolidação dos esforços de vários. Demonstrando grande lucidez nas criticas sobre os equívocos de sua atuação atrelada a outros setores de classes, afirma a necessidade "da classe laboriosa lutar por si", na busca de seus interesses. $\mathrm{O}$ missivista remete, ao grupo acusado ainda em atividade em suas respectivas associações, uma responsabilidade, "fostes os derradeiros depositários dos destinos do extinto partido operário", e uma missão, "reparar o erro e formar um novo partido, porque o operário porto-alegrense precisa de união". ${ }^{24}$ Em inícios de 1893, Castilhos toma posse como governador do estado, e isso poderia sinalizar, especialmente para os seus simpatizantes do meio operário, ${ }^{25}$ a retomada da organização sindical. Esta não ocorreu e veio a guerra civil, mas o documento, como outros dois da mesma lavra publicados anteriormente, ${ }^{26}$ tem que ser entendido nesse sentido de exortação.

Anos depois, Xavier da Costa criticou Steenhagen e os feitos daquele tempo do qual participou, pois era liderança emergente dos tipógrafos. ${ }^{27}$ Primeiro, relembra a organização dos trabalhadores: 
"Fundaram clubes, escolas noturnas, associações beneficentes da classe, chegaram até a publicar um jornal, órgão da mesma.” Depois, fala das fracassadas tentativas de representação parlamentar da classe, especialmente da segunda "nova transação [...] realizada pelo sr. Dr. Castilhos", em resultado da qual os operários tiveram seu representante na Assembleia Constituinte do Estado, mas afirma que este não fez o que se esperava, principalmente "porque era capitalista e partidário da maioria, do PRR”. A seguir, discute as consequências nefastas da partidarização operária daqueles anos:

Parte da classe separou-se espiritualmente do conjunto, inclinando-se à dissidência, outra facção aderiu de fato ao partido federalista e, ainda outra pequena parte, retirou-se descrente da possibilidade de tornar a agremiação operária livre dos efeitos da politicagem crônica, pródiga em espertezas.

Desta forma, quando terminou seu mandato à Constituinte, já o operariado não mais formava um partido apreciável e nem ao menos possuía uma plena vitalidade, uma sociedade beneficente ou uma escola; tudo havia desaparecido. (A Garetinha, 22 nov. 1896).

\section{O projeto das ligas}

Segundo Carone (1984), as ligas derivam do italiano lega, e representam apenas uma forma mais evoluída, para a época, de representação profissional. Entretanto, a acepção em foco é diversa, pois remete a uma proposta política de trabalho em comum, vinculada ao grande setor do trabalho naquele momento. Nesse sentido, pouco importa se, acompanhando o confuso quadro organizativo daquela conjuntura, elas se chamavam liga, congresso, sociedade ou partido, mas sim sua composição e objetivos. Por outro lado, os jornais da época frequentemente utilizaram o termo "liga" com o sentido de "união", inclusive permutando as duas palavras, o que se torna um complicador a mais para o pesquisador. 
De 1888 até 1892, ocorre a criação e extinção de ligas em maior número. Pelotas transforma seu Congresso Operário em liga em 21 de julho de 1890, enquanto outras cidades (Santa Maria, Uruguaiana, Livramento) já possuem associações desse teor, ou as estão criando nesses anos. De meados de 1890 a fins de 1891, as ligas estarão tentando articular-se entre si, como o caso da fusão entre a liga pelotense com aquela da capital exemplifica. Esse processo estaria ocorrendo em todo o Estado, com a liga pelotense tomando a dianteira, como ressalta a iniciativa de enviar seu próprio presidente a Bagé para incentivar a organização dos setores do trabalho naquela cidade. $^{28}$

O passo mais ambicioso das ligas gaúchas foi a agregação de vários candidatos à Constituinte, em nome do "Partido Operário", como discutido anteriormente. Em nome dessa proposta foram feitas concessões, não só pelos militantes da capital como também do interior, pois a liga pelotense seria muito mais próxima do PRR (e, portanto, dos elementos da Liga Operária de Porto Alegre), mas mesmo assim, suas ligações em Porto Alegre foram feitas com o Centro Operário e não com a Liga Operária. Depois da eleição, entretanto, a vitória de Simões Lopes, eleito por ser partidário de Castilhos e não pelos esforços do "Partido Operário", ao lado da polarização e militarização crescente do ambiente político estadual, que é excepcionalmente danosa para as duas associações portoalegrenses, faz ver a impossibilidade de continuar apostando nessa via, ao menos por enquanto.

Em relação ao objetivo de articulação nacional, Pelotas e Rio Grande estão envolvidas desde muito cedo. Rio Grande através de Fortinho e de Rheingantz e seus correspondentes, e Pelotas organizando-se para enviar representantes a todos encontros nacionais. Inicialmente através do primeiro presidente do Congresso Operário, Pinho Louzada, industrial que tenta expandir seus negócios na capital do país e assim serve de representante da liga pelotense. As relações frequentes entre a Liga de Pelotas e o Rio de Janeiro ficam evidentes em representação enviada em setembro de 1891 aos políticos republicanos Drs. Sampaio Ferraz e Demétrio Ribeiro, para a apresentarem ao Congresso Nacional. Nela, alguns representantes das coletividades "operária e proletária" 29 na capital federal denunciam o 
alto custo de vida e fazem considerações sobre a diminuição e compensação de impostos em favor das classes menos favorecidas. O principal representante, presidente do Congresso Operário, Antonio Joaquim Dias da Silva, fala em nome de seu partido e também da Liga Operária de Pelotas.

O Congresso Operário de 1892 no Rio de Janeiro, que criou o Partido Operário Brasileiro, esteve reunido de $1^{\circ}$ de agosto a 5 de setembro de 1892 e contou com um representante da liga, o industrial Joaquim Mariano Jr., que levou mensagem da associação pelotense. Entretanto, o programa ali aprovado era explícito em não aceitar a participação de patrões e proprietários nas associações operárias, ${ }^{30}$ o que, sem dúvida, arrefeceu o entusiasmo das associações gaúchas em relação à articulação nacional com esse segmento do mundo do trabalho, pois ficou evidente que aquela organização não contemplava os mesmos objetivos perseguidos por estas.

Nos dois anos seguintes, a conflituada situação política brasileira (guerra civil no estado e Revolta da Armada) vai auxiliar na falta de organização dos trabalhadores nacionalmente, ${ }^{31}$ que vai ser retomada só em fins de 1895 e com caráter socialista. Contudo, é notável o espaço que foi dado a essas primeiras articulações organizativas industriais e operárias pelos jornais pelotenses de todas as cores partidárias, o que é indício do muito que se esperava em relação à representação de classes na nascente república.

A liderança de Pelotas, em relação às propostas de organização estadual e nacional dentro do estado, é resultado da falta de uma oposição articulada de setores proletários à sua atuação na cidade. A orientação patronal da liga só será contestada politicamente na cidade, a partir de meados de 1893, com a criação do jornal Democracia Social, formado por antigos sócios da mesma e com inclinações socialistas. Mesmo assim, em termos associativos, apenas no final do século se fundará outra associação apenas de trabalhadores, que tentará competir com ela na organização da classe, a União Operária Internacional. Entretanto, a Liga Operária pelotense apresentará fenomenal longevidade, e ocupará o espaço principal de uma organização operária na cidade ainda por décadas. ${ }^{32}$

Rio Grande apresentou maiores problemas para criar uma associação desse tipo, e as diversas tentativas não vingam. $\mathrm{Na}$ realidade, 
há indícios de que ocorra um embate entre o grupo de Rheingantz, que conta com a ajuda de jornalistas (João de Saldanha, João José Cezar e Fernando Pimentel, pelo menos), que tentam construir associações mistas, reunindo trabalhadores e empresários, e grupos de trabalhadores orientados politicamente para a constituição autônoma de suas entidades. Como se constitui na principal cidade portuária do estado, lá as ideias socialistas e anarquistas apareceram muito cedo, pois em 1892, quando de tumultos provocados pela rivalidade oligárquica, já se ouviram vivas à anarquia pelas ruas e houve notícias da prisão de elementos anarquistas em 1894, mesmo ano em que a inauguração da Sociedade União Operária era brindada com vivas ao socialismo em seu desfile pelas ruas.

Fechadas as possibilidades de atuar nacionalmente, em 1892 as ligas operárias do interior entraram em campanha contra a alta do custo de vida, demandando soluções aos intendentes municipais e tentando formar armazéns cooperativos, de forma coligada. Embora nunca completamente desenvolvida, a proposta incluiria movimentação de produtos, de compra e venda entre os vários armazéns cooperados e sua extensão a toda a população urbana, de forma interligada. Preocupavam-se, assim, com reivindicações de caráter popular, como fiscalização do preço dos gêneros alimentícios, criação de armazéns populares e obrigação da venda dos produtos agrícolas a retalho, tentando atuar como representantes da população, propondo comícios e abaixo-assinados como forma de pressão sobre as autoridades municipais. Isso não correspondia exatamente a uma reorientação, pois propostas de defesa dos interesses dos consumidores de baixo poder aquisitivo estavam presentes desde o início, mas elas disseminaram-se como meio de minorar as aflitivas situações dos trabalhadores. O estopim dessas campanhas foi a maior precarização da situação de vida da população urbana, provocada pela crise política, com as dificuldades do abastecimento devido à generalização dos conflitos armados e o açambarcamento dos gêneros alimentícios pelos atravessadores. A essa situação, deve acrescer-se que as tropelias provocadas pelos conflitos armados levaram à paralisação de algumas fábricas, com o consequente desemprego. Não se pode ignorar ainda que essa era uma mobili- 
zação com apelo popular e desgastadora das autoridades constituídas, sendo possível então um componente político nessa campanha.

Com relação a Rio Grande, os contatos da liga pelotense são feitos em abril de 1892 com a Sociedade Cooperativa Filhos do Trabalho, associação exclusiva para trabalhadores negros na cidade (ESTATUTOS..., 1891). Provavelmente, é a partir dessa sociedade que se formará a Liga Operária de Rio Grande, no mês seguinte, com o objetivo de ampliar a representação dos trabalhadores para outros grupos étnicos. Em fins de maio, ocorrerá uma reunião conjunta com a Liga de Pelotas e a associação rio-grandina, a qual é chamada, alternadamente, de Liga Operária e Sociedade Cooperativa, através dos jornais. Pelo que se pode depreender da reunião, a sociedade rio-grandina, em luta contra a carestia de vida na cidade, queria apoio para a formação de armazéns cooperativos, que poderiam permutar gêneros alimentícios pelo estado, proposta que pretendiam difundir entre as demais ligas. A associação pelotense discutiu a ideia, que, deu dar origem à tentativa de instalação de um armazém cooperativo em Pelotas, em junho de 1892, ${ }^{33}$ que fracassa.

Enquanto isso, a recém-criada Liga de Rio Grande é envolvida em mais uma proposta com outros setores, comandada por João de Saldanha, com João José Cesar e Fernando Pimentel, a qual toma a forma da criação de uma sociedade cooperativa, a Sociedade Cooperativa Civil Rio-Grandense, que depois foi abandonada pela ideia da constituição de um simples armazém cooperativo de gêneros alimentícios. $^{34}$

Entretanto, a proposta envolvia muito mais, pois na verdade, tratava-se da fusão da Liga Operária com o Centro Operário, este último uma entidade de que participavam dedicados funcionários (capatazes, diretores, contramestres) das empresas Rheingantz, donos de oficinas, além de funcionários públicos e jornalistas. Provavelmente, foi devido a isso que a proposta não foi avante, não se constituindo a cooperativa, nem se consolidando a fusão. Para os envolvidos no processo, a sensação foi de perda pessoal, como João José Cesar comentou anos depois, em conferência na Liga de Pelotas: 
No Rio Grande, ao lado de um homem de ação enérgica, inteligentíssimo e de variada instrução, o sr. João de Saldanha tentou reunir as duas associações operárias ali existentes, por meio de uma cooperativa, com fins amplamente descritos por aquele ilustre amigo. Nada, porém, foi conseguido e escusa dar os motivos que lhe recordam ainda algumas decepções $[\ldots] .^{35}$

Se a análise desse jornalista republicano dissidente tende a dar ênfase a disputas pessoais, o periódico socialista Echo Operário (24 out. 1897) consegue esclarecer melhor os motivos por que não prosperaram as associações em tela:

A primeira sociedade operária que se fundou nesta cidade teve por título Liga Operária [...]

Logo no seu início, indivíduos que parece viverem só para produzir o mal, imaginando talvez que a Liga Operária pudesse chegar a ser um obstáculo ao desenvolvimento da moderna escravidão industrial, levaram a política desmoralizada da burguesia para o seio da sociedade e quando os bemintencionados, (embora mal orientados) tomavam uma resolução favorável à classe, lá vinham os policastros e mais caterva com os seus conselhos entravar as rodas e mecanismos da sociedade.

Assim aconteceu com a tentativa de uma cooperativa de gêneros alimentícios que quiseram fundar sob a proteção da Municipalidade e que produziu a cisão da sociedade por desacordo com os pescadores de águas turvas a quem alguns bem-avisados operários não queriam ouvir nem atender.

Tudo indica que uma proposta que, para se viabilizar, envolvesse a municipalidade e partidários políticos como esses não conseguiria se manter naquele momento politicamente tão polarizado e explosivo. Além disso, Guedes Coutinho, autor do texto, considera também a intervenção do setor empresarial como fatal para a existência da liga rio-grandense:

Anos 90, Porto Alegre, v. 17, n. 31, p. 111-143, jul. 2010 
Desta cisão, nasceu o esfacelamento da sociedade, pois dividiram-se os operários em duas facções, indo uma fundar outra sociedade [Centro Operário] que era em sua maioria composta de operários das fábricas de tecidos do Sr. Rheingantz à vontade do qual obedeciam por intermédio de pessoas $[\ldots]$ suas simpáticas.

Como era de prever, uma associação operária que media as suas aspirações pela vontade e interesse de um industrialista, considerado o primeiro no Estado, não podia subsistir sob a pena de os operários merecerem o regresso ao cativeiro. $\mathrm{E}$ assim terminaram, com dias de diferença uma à outra as duas tentativas de associações operárias [...] (Echo Operário, 24 out. 1897).

Vê-se, portanto, que o espectro da vontade de Rheingantz em criar uma associação unificada com os trabalhadores ainda perdurava e trazia consequências nefastas para a organização em Rio Grande. Isso só será vencido ao final do ano de 1893, quando finalmente os trabalhadores daquela cidade fundarão sua União Operária, livre da influência do industrial.

Ao que parece, finalmente o desgaste chegara também a Rheingantz: não desanimado com o fracasso da ideia da Liga Agrícola Industrial de 1891, ele tentara, ainda em janeiro de 1892, criar uma Liga Regeneradora, muito saudada por jornais oposicionistas do estado. ${ }^{36}$ Essa liga, que seria um movimento cívico em prol da moralização do governo que ampliasse o interesse oficial na realização de ações visando o desenvolvimento econômico, não se viabilizou. ${ }^{37}$ Em agosto de 1893, irritado com a guerra civil e os entraves aos negócios, tenta formar um Partido (ou Liga) Patriótico, que fosse independente dos dois lados em disputa, buscando que "todas as classes que cooperam para a riqueza pública, manifestem que não se entusiasmam nem pelo sistema parlamentarista, nem pelas doutrinas positivistas" e que o que desejam são leis que promovam a concórdia e lhes permitam trabalhar e progredir em paz. Ele propõe a união de comércio, indústria e meio rural num partido forte em número e influência "para chamar a si o governo 
estadual e nele realizar seu programa", terminando com as rivalidades partidárias. Demonstra o que pensa dos republicanos ao propor a "reforma da Constituição estadual, sobre o molde da constituição federal brasileira, nem governo parlamentarista, nem ditadura presidencial com quase eliminação do poder legislativo". ${ }^{38}$

Rheingantz parece ser o único entre os industriais a ainda apostar na proposta de união comum entre os membros do bloco do trabalho como forma de fazer-se ouvir pelas autoridades constituídas, enquanto os demais empresários já marchavam junto com Castilhos naquele momento. Dessa forma, não tiveram repercussão suas palavras de harmonização de interesses e incentivo ao desenvolvimento. Terminou sofrendo perdas significativas em seus empreendimentos, contabilizando prejuízos em suas fábricas no estado e, coincidentemente, viajando ao exterior no mesmo ano de 1893.

Pode-se dizer que essa proposta de trabalho conjunto entre patrões e trabalhadores declina a partir de 1893, por vários fatores, entre eles a diferenciação interna do grande bloco do trabalho, com cada setor definindo mais claramente seus interesses e priorizando os meios para consegui-los. Assim, as ligas mistas, unindo patrões e empregados, entram em obsolescência política e desaparecem como propostas associativas nos grandes centros, mantendose apenas nas pequenas cidades. ${ }^{39}$ Entretanto, permanece em Pelotas, redimensionada como uma entidade beneficente e recreativa, embora em alguns momentos reivindique o papel de portavoz do operariado local ou até estadual. Como resultado, muitos militantes desse período encerraram sua participação nesse ano desiludidos e/ou amedrontados com os acontecimentos políticos e a destruição de seus sonhos de participação.

Uma pequena parcela das lideranças operárias anteriormente republicanas, considerando-se frustrada, deriva para uma posição socialista, como é o caso do grupo vinculado a João Tolentino de Souza em Pelotas, nucleando-se ao redor do jornal Democracia Social, no conturbado segundo semestre de 1893. Nesse jornal, a proposta socialista já está claramente explicitada e, em que pese seu pouco tempo de vida, o periódico vai auxiliar a espalhar a ideia pelo Estado, paradoxalmente depois de sua extinção, com Guedes Coutinho em 
Rio Grande (Echo Operário), Eduardo Mallmann em Alegrete ( $O$ Social), além do próprio João Tolentino de Souza, que em Porto Alegre incorpora-se ao grupo que vai formar a Liga Operária Internacional, em 1895.

$\mathrm{Na}$ capital, temos que os dois grupos vinculados aos republicanos também conheceram trajetórias diferenciadas, pois enquanto a maioria termina abandonando as associações de classe e se transformando em combatente de um ou outro lado, outros conseguem manter uma certa distância desse processo (em que pesem eventuais simpatias pessoais) e vão reaparecer mais tarde, vinculados a grupos socialistas, novamente apostando na organização independente de classe, como é o caso de Nicolau Tolentino da Soledade.

Concluindo, retoma-se o início: se através de pesquisa em jornais diários se pode verificar uma organização tão articulada e até surpreendente para aqueles primeiros anos da República, sem dúvida um estudo mais amplo e que contasse com maior documentação, como arquivos pessoais dos envolvidos ou atas da Sociedade Auxiliadora da Indústria Nacional (para projetar suas articulações junto ao setor empresarial, por exemplo), poderia talvez aprofundar muito mais os passos seguidos por aquelas primeiras lideranças do bloco do trabalho na busca da organização do setor para fazer frente aos novos desafios advindos com a república. Entretanto, para os objetivos deste artigo, fazer a ligação entre os esforços até então aparentemente desconectados das várias associações operárias e as atitudes dos homens que abraçaram essas ideias, foi o suficiente. De quebra, conseguiu-se também avaliar o lento, mas progressivo, emergir de certa consciência de classe nos atores desse estudo, ou repassada a seus sucessores, a partir da experiência vivida e concreta de um momento extremamente difícil e perigoso para aqueles que o vivenciaram.

\section{Workers League Project in Rio Grande do Sul in the early Republic}

Abstract: In the early years of the republic, the gatherings of workers, in Rio Grande do Sul, tried to organize to manage to intervene in national and state politics, through Workers Leagues with a proposition to form a workers party with electoral expression. This project was taken on mainly by leaderships in the three main cities in the state, Porto Alegre, Pelotas and Rio Grande. However they were 


\section{O projeto das ligas operárias...}

not able to overcome the obstacles in their path, mostly organizational ones, they suffered also effects of parties polarization and eventually from the civil war that devastated the state. With the failure of such project, both politically and organizationally, it also closed all possibilities for an independent participation of workers in the states political scene, after the period studied.

Keywords: Republican workers. Workers Leagues. Labor parties. First republic. Labor world.

\section{Notas}

${ }^{1} \mathrm{O}$ conteúdo do manifesto, do qual não se conseguiu o original de $A$ Federação, saiu publicado no jornal Echo Popular de 10/04/1890. Foi transcrito em Carone (1984). ${ }^{2}$ Essa questão deve ser deixada em aberto, enquanto não se conseguir mais testemunhos diretos ou indiretos a respeito. Mas talvez a pesquisa em arquivos pessoais dos chamados dissidentes entre os republicanos poderia revelar dados interessantes, dado sua maior proximidade com os trabalhadores de menor valor aquisitivo, posteriormente (BAK, 2000; PESAVENTO, 1988).

3 A Reforma, artigo "Contra fatos", transcrito em O Nacional (3 mar. 1890); ver também o Mercantil (28 fev. 1890), editorial, e em dias seguintes. Nas citações de documentos antigos a grafia foi atualizada segundo a norma vigente.

${ }^{4}$ O Trabalho Nacional (24 mar. 1890, 31 mar. 1890).

${ }^{5}$ Cruz da Silva foi presidente geral do Congresso Operário e, nessa função, encaminhou uma representação ao Congresso Nacional contra a alta do custo de vida e pela nacionalização do comércio a varejo, em agosto de 1891. Nessa atuação, tinha representação da Liga Operária de Pelotas (CARONE, 1984, p. 191).

${ }^{6}$ E provavelmente a Liga Agrícola Industrial, de Porto Alegre, criada pouco depois. Em 13 de outubro de 1888, A Pátria noticia que ele havia solicitado passagem ao presidente da província para ir a Porto Alegre "entender-se com a sociedade industrial de lá", mas que foi negada, a pretexto de falta de verbas.

${ }^{7}$ Opinião Pública (1 jul. 1897).

${ }^{8}$ A referência é o Diário de Pelotas (16 out. 1888), mas esse assunto também é abordado, na mesma data, por A Pátria (15 out. 1888) e Onze de Junho (30 out. 1888).

${ }^{9}$ Era o maior industrial de Rio Grande na época, possuindo fábrica de tecidos com cerca de mil trabalhadores; nessa época, tentava também estabelecer negócios no Rio de Janeiro.

${ }^{10}$ Relatório da associação, por seu secretário Virgilio J. Porciúncula, publicado em $O$ Trabalho Nacional (3 fev. 1890).

Anos 90, Porto Alegre, v. 17, n. 31, p. 111-143, jul. 2010 


\section{Beatriz Ana Loner}

${ }^{11}$ Notícias dos jornais pelotenses Correio Mercantil (29 mar. 1890) e A Pátria (20 maio 1890).

12 Os indícios que levam a essa conclusão é que, em 1892, ela é chamada, indiferenciadamente, pelas duas denominações, em jornais que relatam suas negociações com a Liga de Pelotas e também porque o presidente e alguns membros da diretoria da Liga Operária de Rio Grande são os mesmos da sociedade Filhos do Trabalho. ${ }^{13}$ Relatório feito pela comissão executiva do Partido Operário do Brasil, de São Paulo, e apresentado ao Congresso da Internacional Socialista em Zurique em 1893. O texto integral do relatório foi transcrito em Haupt (1973) e, conferindo-o, vê-se que não é citada nenhuma associação gaúcha.

14 A Federação (23 set. 1887).

15 A Federação (31 jul. 1888). Também há noticias sobre ela nas edições dos dias 17 de julho de 1888 (criação) e 6 de setembro de 1888. Em 18 de julho de 1889 ela convida para as solenidades de seu primeiro aniversário, em 21 de julho desse ano. ${ }^{16}$ A notícia saiu pelo Onze de Junho dos dias 17 e 21 de janeiro de 1889. Também aparece em $A$ Federação (14 jan. 1889), mas sem referência à criação de um partido.

${ }^{17}$ Nesse dia, a comemoração pela abolição degenera em conflito entre polícia e manifestantes, com saldo de um morto, vários feridos e a queda do governo estadual (BAK, 2000; PACHECO, 2001). Toda a visão sobre as manifestações e articulações partidárias na capital seguirá de perto a visão desses autores.

${ }^{18}$ Essa hipótese fica consideravelmente reforçada quando se sabe que seu jornal, $O$ Productor, tinha uma edição em português e uma em alemão (Der Productor), ambas iniciadas em agosto de 1889, como consta em Petersen (1989, p. 72).

${ }^{19}$ O Rio Grande (26 dez. 1890) (arquivo pessoal de Joan Bak, a quem agradeço por partilhar essa fonte).

${ }^{20}$ A Federação (6 dez. 1890) e A Pátria (9 e 11 dez. 1890). Ricardo Pacheco (2001, p. 104-105) apresenta a entidade como sendo fundada em 18 de janeiro de 1891, a partir de notícia em $A$ Federação (19 jan. 1891).

${ }^{21}$ Embora já presente no texto apresentado a congresso em 2000, Bak aprofunda estas ideias no primeiro capítulo do livro ainda inédito que está escrevendo sobre as relações entre estado e trabalhadores no Rio Grande do Sul. Agradeço imensamente à autora pela oportunidade de consultar esse capítulo antes mesmo de publicado, o que me valeu na escrita deste artigo, pois esclareceu razões e motivos da atuação e prática operária naquele momento e permitiu integrar várias informações antes descosturadas.

${ }^{22}$ Jornal do Commercio de 16 de abril de 1891 (PACHECO, 2001, p. 117).

${ }^{23}$ Pacheco (2001, p. 116-118). Bak também discute sua posição (inédito).

${ }^{24}$ A Gazetinha (15 jan. 1893).

${ }^{25}$ Uma leitura mesmo superficial de $A$ Gazetinha deixa entrever uma simpatia maior pelo governo de Castilhos do que pelos seus antecessores.

Anos 90, Porto Alegre, v. 17, n. 31, p. 111-143, jul. 2010 
${ }^{26}$ Outras duas cartas, com a assinatura de Eloy da Gama e exortando a organização operária em bases independentes já haviam sido publicadas em abril de 1892, quando se esperava houvesse eleições (PETERSEN, 2001, p. 88-91).

${ }^{27}$ Em fins de 1890, um Francisco Costa participa da criação de sociedade tipográfica em Porto Alegre, como secretário substituto, o que o próprio Xavier admite ter sido, posteriormente (ver A PÁTRIA, 31 dez. 1890; SCHMIDT, 2004).

${ }^{28}$ A Pátria (6 abr. 1891) e Gazeta da Tarde (18 maio 1892).

${ }^{29}$ Essa curiosa denominação origina-se do fato de que essa representação é assinada por cinco pequenos partidos operários, dos quais um se nominava "Proletário". A falta de maiores informações impede alcançar o exato sentido dessa diferenciação, mas ressalte-se que ela foi considerada tão importante que constou da representação (CARONE, 1984, p. 191)

${ }^{30}$ Ver o art. 21 daquele programa, disponível em Carone (1984, p. 304-308). Quanto à participação da liga, ver Gaz̧eta da Tarde (26 jul. 1892, 17 ago. 1892).

${ }^{31}$ Há uma tendência a minimizar os efeitos da guerra civil sobre o operariado, mas indiretamente seu impacto pode ser avaliado pelo fato de que a reunião que resolveu criar um novo partido operário, agora socialista, em 1895 na capital da república, foi inicialmente chamada com o sentido de "manifestar ao presidente da República o júbilo da classe operária sobre a Paz do sul" (CARONE, 1984, p. 310). Contudo, os poucos que atenderam ao convite discordaram, pois já havia muitas manifestações nesse sentido, e esta pareceria bajulação. Assim, decidiram chamar outra reunião, para fundar um partido. Ou seja, há vinculação direta entre estabilidade política e social e organização da classe (CARONE, 1984, p. 310).

${ }^{32}$ Sobre isso, ver Loner (2001).

${ }^{33}$ Variados jornais dão cobertura aos entendimentos entre as duas entidades, como Gazeta da Tarde, (29 maio 1892, 11, 13 e 17 jun. 1892) e também Correio Mercantil $(27,29$ e 31 maio 1892).

${ }^{34}$ A história é documentada com ênfase na atuação de João de Saldanha junto à liga, pela Gazeta da Tarde (20 abr. 1892, 17 maio 1892). Também o Correio Mercantil (18 maio 1892) noticia a reunião do Centro Operário com a Liga Operária para discutir os estatutos da Cooperativa Civil Rio-Grandense, organizada pelo senhor João de Saldanha, que leu os estatutos. Seria uma cooperativa a preço baixo para favorecer até os mais pobres, pois mesmo os não sócios poderiam comprar. Falaram ainda a senhora dona Revocata de Mello e os senhores J. G. Barreto, Domenico Calicchio e Abílio Freitas. Em 21 de maio de 1892 o mesmo jornal noticia que foi abandonada a ideia da fundação de uma cooperativa e resolveu-se criar um armazém cooperativo, como o que existe nas fábricas Rheingantz. Foi incumbido de confeccionar o estatuto desse armazém o senhor Fernando Pimentel. Posteriormente, no dia 14 de julho de 1892 , noticia sua diretoria.

${ }^{35}$ Correio Mercantil (21 ago. 1905).

Anos 90, Porto Alegre, v. 17, n. 31, p. 111-143, jul. 2010 
${ }^{36}$ As posições políticas de Rheingantz ainda estão merecendo um estudo específico. Ele não era imune a articulações políticas, tanto que se tornou fornecedor do exército no final do período imperial. Ainda é evidente que, apesar de reclamar também dos federalistas, está sempre mais próximo dos oposicionistas do que do castilhismo entre 1890 e 1993.

${ }^{37}$ Ver a Gazeta da Tarde (8 jan. 1892), que traz seu manifesto, e editoriais dos dias 29 de janeiro e 27 de fevereiro de 1892 . O jornal, ainda surpreso com os acontecimentos políticos e a atitude raivosa dos republicanos contra quem ousasse desafiá-los, acredita nessa proposta e tenta difundi-la.

${ }^{38}$ Correio Mercantil (26 ago. 1893).

${ }^{39}$ Com isso não se quer dizer que não haverá várias outras propostas, fora desse período, de criação de entidades em comum. A experiência demonstrou que isso é fato recorrente na história das organizações operárias. Aqui só se quer assinalar que o tempo histórico de possível vigência de um projeto desses já se havia esgotado, no Brasil e no Rio Grande do Sul, e que, a partir de então, as entidades assim criadas terão uma vitalidade essencialmente limitada.

\section{Referências}

A FEDERAÇÃO. Porto Alegre, 1884-1937.

A GAZETINHA. Porto Alegre, 1891-1900.

A PÁTRIA. Pelotas, 1886-1891.

A REFORMA. Porto Alegre, 1869-1912.

CORREIO MERCANTIL. Pelotas, 1875-1915.

DEMOCRACIA SOCIAL. Pelotas, 1893-1893.

DIÁRIO DE PELOTAS. Pelotas, 1868-1889.

ECHO POPULAR. Rio de Janeiro, 1869-[?].

ECHO OPERÁRIO. Rio Grande,

GAZETA DA TARDE. Pelotas, 1891-1892.

JORNAL DO COMMERCIO. Porto Alegre, 1864-1911.

O MERCANTIL. Porto Alegre, 1874-[?].

O NACIONAL. Pelotas, 1889-1892.

ONZE DE JUNHO. Pelotas, 1868-1889.

Anos 90, Porto Alegre, v. 17, n. 31, p. 111-143, jul. 2010 


\section{O projeto das ligas operárias...}
O OPERÁRIO. Porto Alegre, 1889-1889.
OPINIÃO PÚBLICA. Pelotas, 1896-1962.
O PRODUCTOR. Porto Alegre, 1889-1891.
O SOCIAL. Alegrete, 1897-1899.
O TRABALHO NACIONAL. Rio Grande, 1889-1891.
O SUL DO BRASIL. Pelotas, 1889-1898.

BAK, J. Incorporating “the proletariat” in Brazil's First republic: founding moments in Rio Grande do Sul-1889-1892. In: PROCEEDINGS of the American Historical Association, 2000. Reference \# 10485.

CARONE, E. Movimento operário no Brasil (1877-1944). São Paulo: Difel, 1984.

ESTATUTOS da Sociedade Cooperativa Filhos do Trabalho. Rio Grande: Typographia do Bisturi, 1891.

HAUPT, G. Militants sociaux-démocrates allemands au Brésil (1893-1896). Le Mouvement Social, Paris, n. 84, p. 47-61, 1973.

KOVAL, B. História do proletariado brasileiro (1857-1967). São Paulo: Alfa-Omega, 1982.

LINHARES, J. O operariado brasileiro no século XIX. Revista Brasiliense, n. 49, p. 29-43, 1963.

LONER, B. Construção de classe: operários de Pelotas e Rio Grande (1888-1930). Pelotas: EDUFPel, 2001.

MARÇAL, J. B. As primeiras lutas operárias no Rio Grande do Sul. Porto Alegre: Globo, 1985.

MORITZ, G. Acontecimentos politicos do R. G. do Sul: 89-90-91. Porto Alegre: Tipografia Thurmann, 1939.

PACHECO, R. O cidadão está nas ruas. Porto Alegre: EDUFRGS, 2001.

PÁDUA, J. A. A capital, a República e o sonho: a experiência dos partidos operários de 1890. Revista Dados, Rio de Janeiro, v. 28, n. 2, p. 163-192, 1985.

PANSARDI, M. O movimento operário e a república. Estudos de Sociologia, v. 5, p. 87-99, 1998.

PESAVENTO, S. A burguesia gaúcha: dominação do capital e disciplina do trabalho: RS 1889-1930. Porto Alegre: Mercado Aberto, 1988.

PETERSEN, S. Guia para o estudo da imprensa periódica dos trabalhadores do Rio Grande do Sul (1874-1940). Porto Alegre: EDUFRGS, 1989.

Anos 90, Porto Alegre, v. 17, n. 31, p. 111-143, jul. 2010 


\section{Beatriz Ana Loner}

- Que a União Operária seja nossa pátria. Santa Maria: EDUFSM, 2001.

SCHMIDT, B. Em busca da terra da promissão. Porto Alegre: Palmarinca, 2004.

Recebido em: 05/06/2010

Aprovado em: 16/07/2010

Anos 90, Porto Alegre, v. 17, n. 31, p. 111-143, jul. 2010 